УДК 004.7

В. Ю. Зубок

ТОВ «Інформаційний центр «Електронні вісті» вул. Максима Кривоноса, 2-А, 03037 Київ, Україна

\title{
Аналіз характеристик нових мереж обміну інтернет-трафіком
}

Проведено дослідження характеристик трьох українських мереж обміну інтернет-трафіком. Порівняння таких характеристик як розподіл ступеню, середній коротший шлях, коефіцієнт кластеризаиії дозволило знайти в топології циих мереж як спільні риси, так і суттєві відмінності, які можуть бути використані в процесі пошуку оптимальних вузлів з точки зору приєднання до мережі Інтернет чи розміщенні в ній інформаційних ресурсів.

Ключові слова: мережі обміну трафіком, топологічна відстань, транзитивність.

\section{Вступ}

Оскільки у складних мережах топологічна відстань (мінімальна кількість ретрансляції повідомлення між транзитними вузлами) є інтегральним критерієм швидкості передачі, то кращим для приєднання, з технологічної точки зору, є вузол 3 найменшим значенням середнього коротшого шляху в даному сегменті мережі.

Перші мережі обміну трафіком — «network access points» — 3'явилися в ARPANET ще до того, як термін Інтернет набув популярності. Ідея їхнього заснування - додержуватися чітко визначених процедур підключення та правил взаємодії між мережами учасників. Сьогодні в Свропі функціонує багато мереж обміну трафіком. Вони мають різну кількість учасників та обсяги трафіка, різні процедури підключення, а головне - різну політику маршрутизації та взаємодії між учасниками. Але кожна 3 них має свій вплив на топологію зв'язків між автономними системами в Інтернеті.

У топології сучасного Інтернету мережі обміну трафіком чи біржі трафіка (Internet Exchange Points, IXPs) відіграють дуже важливу роль. Однією 3 «класичних» мереж обміну трафіком є Українська мережа обміну трафіком (UA-IX), заснована в 2001 році. Але протягом двох останніх років у UA-IX спостерігається від’ємна динаміка трафіка (рис. 1). Це пов'язано з тим, що на український сегмент Інтернет значно впливають нові мережі.

(C) В. Ю. Зубок 


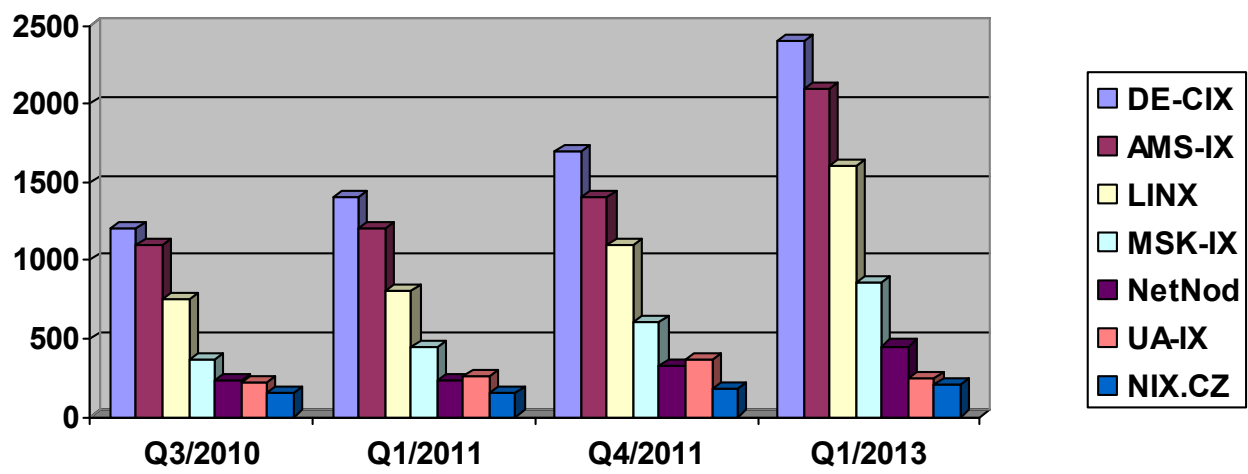

Рис. 1. Обсяги транзитного трафіка (пікове навантаження в Гбіт) європейських IXР протягом 2010-2013 років

У попередніх роботах $[1,2]$ мережа UA-IX досліджувалась як складна мережа. Вивчався розподіл ступеню вузлів, діаметр мережі, середній найкоротший шлях, показник кластеризації мережі та інші параметри. Ця робота присвячена дослідженню відносно нових мереж обміну — DTEL-IX та Giganet.

\section{Мета роботи}

Роботу виконано за результатами дисертаційного дослідження з розробки методики застосування математичного апарату складних мереж для аналізу комп'ютерних мереж, які під’єднані до Інтернету. Метою роботи є апробація методики аналізу властивостей окремих вузлів та їхнього впливу на властивості мережі в цілому, а також виділення критеріїв пошуку оптимальних вузлів 3 точки зору приєднання до мережі.

\section{Методика дослідження}

Досліджувані сегменти мережі Інтернет є за своєю суттю складними мережами $[3,4]$. У складних мережах досліджуються наступні параметри:

1) розподіл ступеню $P(k)$ :

$$
P(k)=\frac{\langle N(k)\rangle}{N}
$$

де $N$ - кількість вузлів у мережі; $<N(k)>-$ середня кількість вузлів ступеню $k$;

2) середній геодезичний шлях $l$ у мережі $3 n$ вузлів:

$$
l=\frac{2}{n(n-1)} \sum_{i>j} d_{i j},
$$

де $n$ - кількість вузлів у мережі; $d_{i j}$ - найкоротший шлях між вузлами $i$ та $j$; 
3) коефіцієнт кластеризації для вузла $C_{i}$ :

$$
C_{i}=\frac{2 e_{i}}{k_{i}\left(k_{i}-1\right)},
$$

де $e_{i}$ - фактична кількість зв'язків між сусідами вузла $i ; k_{i}$ - максимально можлива кількість таких зв'язків;

4) транзитивність - середній показник кластеризації мережі $C$ :

$$
C=\frac{1}{N} \sum_{i=1}^{N} C_{i}
$$

де $N$ - кількість вузлів у мережі;

5) глобальна ефективність $E$ :

$$
E=\frac{2}{n(n-1)} \sum_{i>j} \frac{1}{d_{i j}},
$$

де $n$ - кількість вузлів в мережі; $d_{i j}$ - найкоротший шлях між вузлами $i$ та $j$;

6 ) вразливість $V$ до вилучення вузла $i$ :

$$
V_{i}=\frac{E-E_{i}}{E},
$$

де $E_{i}$ - глобальна ефективність після вилучення вузла $i$.

Отримані дані використовуються для дослідження відносин між вузлами (зокрема, комерційних і геополітичних), моделювання нових алгоритмів маршрутизації тощо. Також $є$ можливість використання отриманих знань для вирішення практичних задач при проектуванні та подальшій оптимізації взаємозв'язку підмереж і вузлів Інтернету.

Вхідними даними для дослідження є таблиці маршрутизації, які отримані 3 серверів маршрутизації учасників відповідних мереж обміну трафіком. Вузлами мережі є автономні системи (AS), що ідентифікуються за унікальними номерами. Ребрами мережі є зв'язки між автономними системами, встановлені за допомогою безпосередньої взаємодії за протоколом глобальної маршрутизації BGP-4.

\section{Стислий опис досліАжуваних мереж}

Мережа UA-IX заснована в 2001 році. Станом на квітень 2013 р. в UA-IX присутні анонси 132-х учасників, що безпосередньо підключені до цієї мережі. Вони обмінюються через UA-IX анонсами, які походять від 1984-х вузлів - автономних систем, що з'єднані 2240 безпосередніми зв'язками. 
Мережа обміну трафіком DTEL-IX заснована в 2009 році. Станом на травень 2013 налічує 82 учасники, з них безпосередніх учасників, що надсилають анонси - 73. Кількість AS, що спостерігаються в анонсах — 2012, та між ними є видимими приблизно 2200 зв'язків.

Мережа обміну трафіком Giganet $€$ наймолодшою - перші зв'язки в ній було встановлено в 2012 році. Станом на травень 2013 року вона налічує 45 учасників, які анонсують префікси, у шляхах яких можна побачити 2305 автономних систем та приблизно 2450 безпосередніх зв’язків.

\section{Характеристики досліАжуваних мереж}

Розподіл ступеню досліджуваних мереж наведений на рис. 2 у подвійній логарифмічній шкалі. У всіх трьох мереж він апроксимується степеневою функцією, тобто зберігає типовий безмасштабний характер (scale-free). У таких мережах лічені вузли є дійсно важливими «транзитерами» анонсів, а більша частина автономних систем мають ступінь 1 , тобто не $\epsilon$ посередниками і не виконують транзитних функцій, вони є так званими «пелюстками».

Інші порівняльні характеристики мереж наведено в табл. 1.

Таблиця 1. Порівняння характеристик мереж UA-IX, DTEL-IX тa Giganet

\begin{tabular}{|c|c|c|c|c|}
\hline № & Назва параметра & UA-IX & DTEL-IX & Giganet \\
\hline 1 & Кількість вузлів & 1984 & 2012 & 2305 \\
\hline 2 & Кількість зв’язків & 2240 & 2200 & 2450 \\
\hline 3 & Діаметр мережі & 9 & 9 & 10 \\
\hline 4 & Кількість тупикових вузлів & 1677 & 1707 & 2012 \\
\hline 5 & Кількість транзитних вузлів & 307 & 305 & 293 \\
\hline 6 & Середній коротший шлях & 4,05 & 4,843 & 4,87 \\
\hline 7 & Глобальна ефективність & 0,263 & 0,219 & 0,202 \\
\hline 8 & Транзитивність & 0,039 & 0,0098 & 0,0083 \\
\hline
\end{tabular}

Досліджувані сегменти мереж є подібними за кількістю вузлів і зв'язків i, на перший погляд - за топологією: подібний розподіл ступеню, велика кількість вузлів з 1-м зв'язком, але при більш глибокому аналізі топології.

У табл. 2 наведено характеристики «бекбону» (фрагменту найбільш тісно пов'язаних вузлів) кожної мережі, яке було виділено із загальної кількості вузлів шляхом «видалення пелюсток» [5].

Таблиця 2. Порівняння характеристик «бекбонів» мереж

\begin{tabular}{|c|c|c|c|c|}
\hline № & Назва параметра & UA-IX & DTEL-IX & Giganet \\
\hline 1 & Кількість вузлів & 435 & 305 & 54 \\
\hline 2 & Кількість зв'язків & 889 & 357 & 64 \\
\hline 3 & Діаметр мережі & 7 & 8 & 7 \\
\hline 4 & Середній коротший шлях & 3,03 & 3,927 & 3,434 \\
\hline 5 & Глобальна ефективність & 0,354 & 0,279 & 0,389 \\
\hline 6 & Транзитивність & 0,259 & 0,05 & 0,2 \\
\hline
\end{tabular}




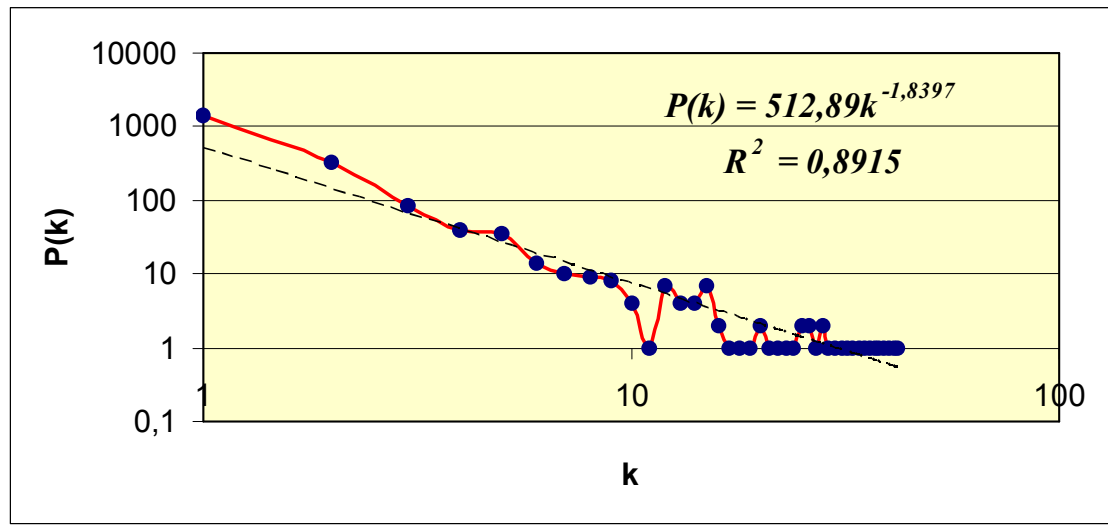

a)

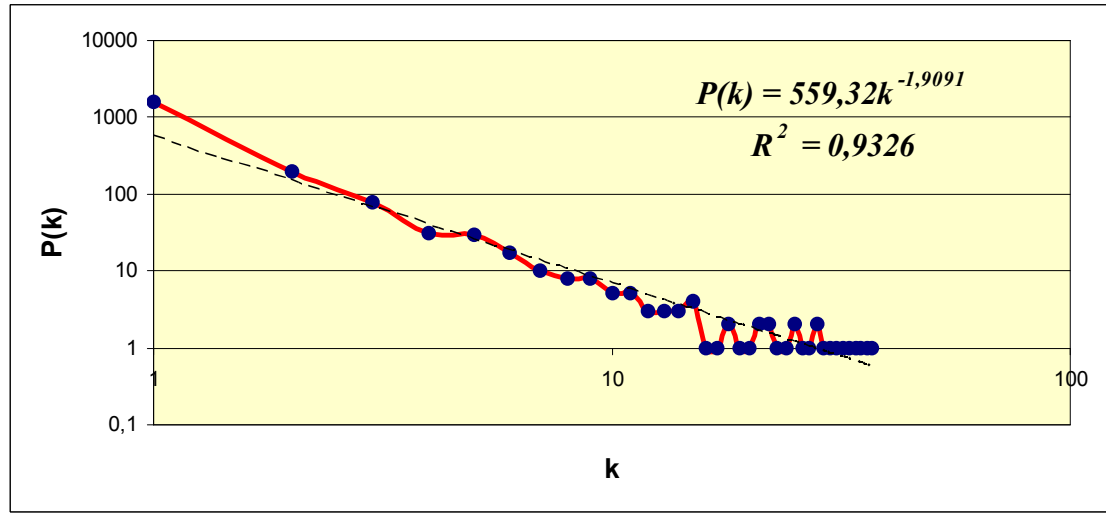

б)

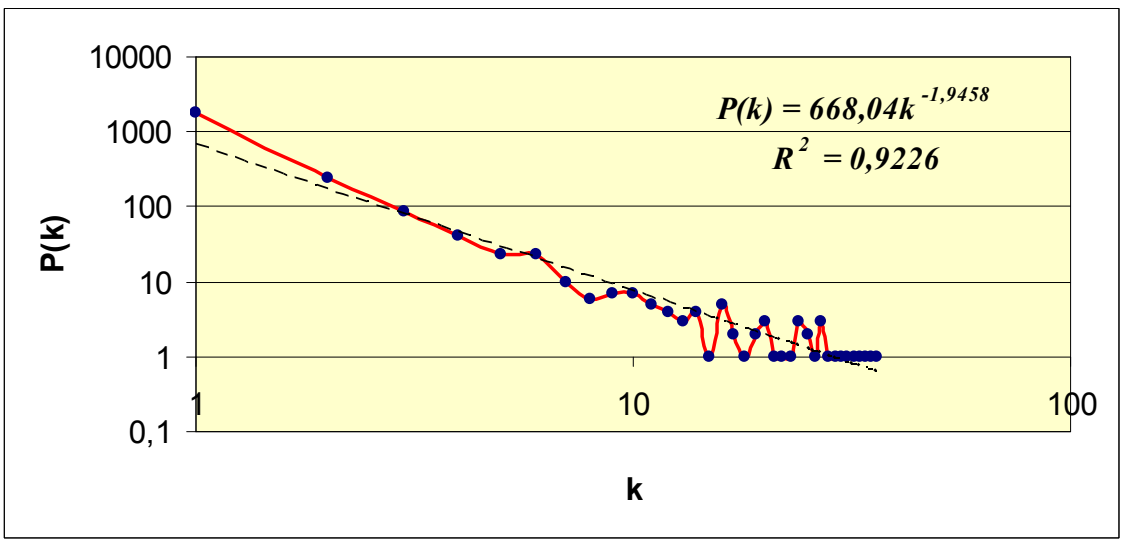

в)

Рис. 2. Розподіл ступеню $P(k)$ у мережах: а) UA-IX; б) DTEL-IX; в) Giganet (графік апроксимованої функції показаний переривчастою лінією)

На рис. 3 наведено декілька порівняльних діаграм, що наочно демонструють динаміку змін характеристик мереж у міру відсіювання нетранзитних вузлів. 


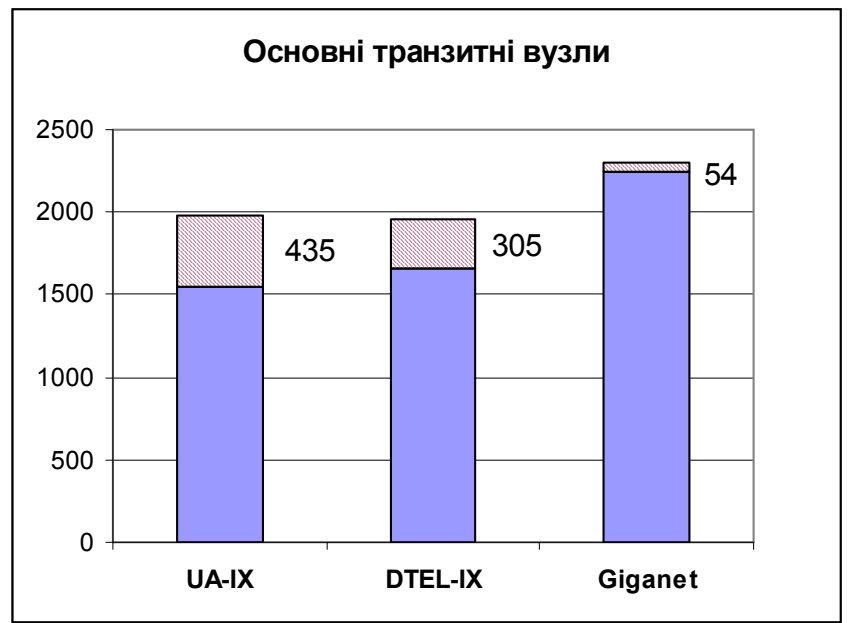

a)

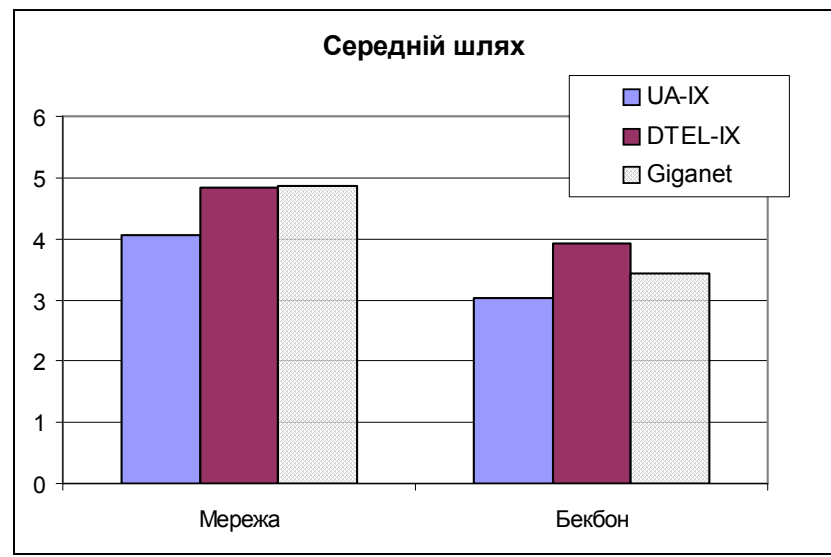

б)

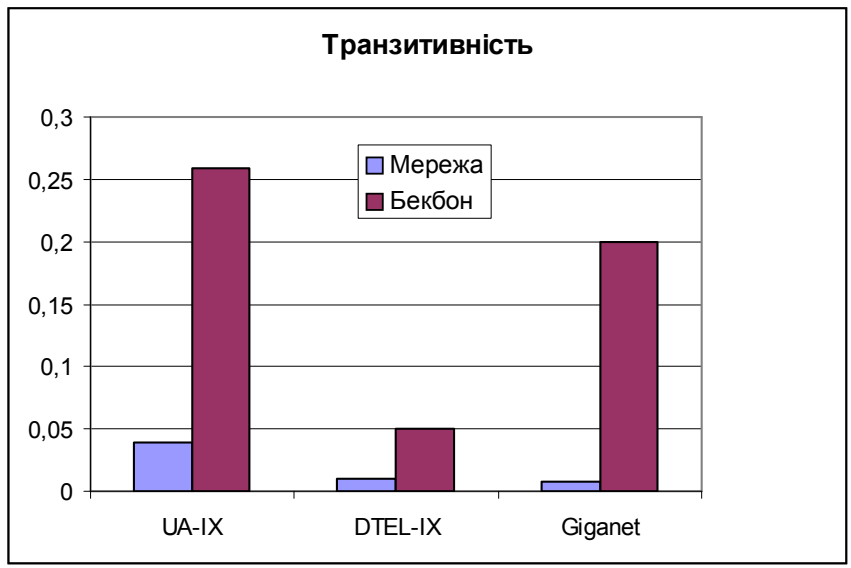

в)

Рис. 3. Співвідношення тупикових і транзитних вузлів (а), середнього шляху (б) та транзитивності (в) у мережах UA-IX, DTEL-IX та Giganet 


\section{Висновки}

У роботі проведено дослідження характеристик трьох українських мереж обміну інтернет-трафіком. За основними і найбільш наочними характеристиками кількістю вузлів і зв'язків — ці мережі є подібними. Але більш глибокий аналіз демонструє, що суттєві відмінності в розподілі зв'язків між вузлами. Ці відмінності між мережами обумовлені як їхнім «віком», так і різницею в політиках маршрутизації (правилах взаємодії учасників). Так, UA-IX є єдиною із трьох мереж, де є обов'язковим так званий «відкритий пірінг» - обов'язкова передача маршрутів через центральний вузол. У двох інших мережах «відкритий пірінг» $є$ опцією, а загалом - учасники мережі мають право встановлювати приватні зв'язки на власний розсуд.

Так, мережа UA-IX має найвищий показник кластерності, що характеризує іï як найкращого транзитера, і це підтверджується значенням середнього найкоротшого шляху. Найбільш молода із мереж Giganet демонструє найдовший середній шлях тому, що середовище найбільш зв'язаних між собою вузлів цієї мережі складається лише з 3 \% вузлів (у UA-IX - $323 \%$ ), а коефіцієнт кластерності цього середовища $є$ на $20 \%$ нижчим, ніж в UA-IX. У мережі DTEL-IX основні транзитні вузли $є$ найменш зв'язаними між собою, через це середній шлях через ядро мережі $є$ найдовшим, а його глобальна ефективність — найнижчою.

1. Зубок В.Ю. Исследование сетевых параметров украинского сегмента Интернет / Д.В. Ланде, В.Ю. Зубок, В.Н. Фурашев // Открытые информационные и компьютерные технологии: сб. науч. трудов. - Вып. 40. - Харьков: Нац. аэрокосм. ун-т «ХАИ». — 2008. — С. 235-242.

2. Зубок В.Ю. Європейські мережі обміну Інтернет-трафіком та їхній вплив на зв'язність між автономними системами / В.Ю. Зубок: зб. наук. праць IПМЕ ім. Г.С. Пухова НАН України. - К., 2011. - Вип. 56. - С. 19-28.

3. Barabasi A.-L. Scale-Free Networks / A.-L. Barabasi, E. Bonabeau // Scientific American. 2003, May. - P. 50-59.

4. Ландэ Д.В. Интернетика. Навигация в сложных сетях: модели и алгоритмы / Ландэ Д.В., Снарский А.А., Безсуднов И.В. — М.: Книжный дом «Либроком», 2009. — 264 с.

5. Genomic Analysis Reveals a Tight Link Between Transcription Factor Dynamics and Regulatory Network Architecture / Raja Jothi, S. Balaji, Arthur Wuster [et al] // Molecular Systems Biology 5 // EMBO and Macmillan Publishers Limited. — 2009. — art. N 5.

Надійшла до редакції 27.05.2013 